\title{
Measurement of Change in Lower Eyelid Position in Patients Undergoing Transcutaneous Skin-Muscle Flap Lower Eyelid Blepharoplasty
}

Babar Sultan, MD; Dane J. Genther, MD; Stephen W. Perkins, MD

IMPORTANCE Transcutaneous lower eyelid blepharoplasty is a commonly performed procedure with a postoperative risk of eyelid malposition.

OBJECTIVE To quantify the change in lower eyelid position after transcutaneous lower eyelid blepharoplasty.

DESIGN, SETTING, AND PARTICIPANTS This retrospective medical record review describes patients who underwent transcutaneous blepharoplasty at a private facial plastic surgery practice. Patients with less than 3 months of follow-up, a history of periocular trauma, and concurrent midface lift were excluded.

INTERVENTIONS Bilateral skin-muscle flap lower eyelid blepharoplasties with possible tarsorrhaphy, canthopexy, or canthoplasty as indicated.

MAIN OUTCOMES AND MEASURES Lower eyelid position determined by measurement of preoperative and postoperative pupil to eyelid and lateral limbus to eyelid distances.

RESULTS Data from 100 consecutive patients (mean age, 56.7 years; 92 female [92.0\%]) undergoing bilateral skin-muscle flap lower eyelid blepharoplasty were analyzed. The mean increase in distance was $0.33 \mathrm{~mm}(95 \% \mathrm{Cl}, 0.24-0.42 \mathrm{~mm})$ from the pupil to the lower eyelid margin and $0.32 \mathrm{~mm}(95 \% \mathrm{Cl}, 0.23-0.41 \mathrm{~mm})$ from the lateral limbus to the lower eyelid margin at final follow-up. For both measurements, patients undergoing concurrent canthopexy had a significantly greater change in eyelid position $(P<.001)$. Men had a greater change in the distance of pupil to lower eyelid compared with women $(0.76 \mathrm{~mm} ; 95 \% \mathrm{Cl}$, $0.44-1.08 \mathrm{~mm}$, vs $0.30 \mathrm{~mm} ; 95 \% \mathrm{Cl}, 0.20-0.39 \mathrm{~mm}$, respectively; $P=.008)$ at final follow-up. Two patients required revision procedures secondary to eyelid malposition, and 25 patients had new onset of dry eye symptoms.

CONCLUSIONS AND RELEVANCE Transcutaneous skin-muscle lower eyelid blepharoplasty with selective performance of canthoplasty or canthopexy causes a small, predictable eyelid position change in this population with a low rate of revision procedures.

LEVEL OF EVIDENCE 3.

Author Affiliations: Sultan Facial Plastic and Reconstructive Surgery, Towson, Maryland (Sultan); Department of Otolaryngology-Head and Neck Surgery, Johns Hopkins School of Medicine, Baltimore, Maryland (Genther); Meridian Plastic Surgeons, Indianapolis, Indiana (Perkins); Department of Otolaryngology-Head and Neck Surgery, Indiana University School of Medicine, Indianapolis (Perkins).

Corresponding Author: Babar Sultan, MD, Sultan Facial Plastic and Reconstructive Surgery, 100 West Rd, Ste 111, Towson, MD 21204 (drsultan@sultanfacialplastics.com). 
L ower eyelid blepharoplasty is a common facial surgical procedure with significant aesthetic and functional considerations. Age-related changes to the lower eyelid complex include skin texture changes, resulting in rhytids, orbicularis oculi hypertrophy, and pseudoherniation of orbital fat. ${ }^{1}$ The 2 most common techniques to address these changes are the transcutaneous skin-muscle flap approach and the transconjunctival approach. The transcutaneous method has the advantages of an anatomical approach with excellent visualization and the ability to simultaneously address skin redundancy and muscular hypertrophy, but the potential for scar contracture in the plane between the orbital septum and orbicularis oculi muscle confers a risk of eyelid malposition and ectropion. ${ }^{2}$ However, the transconjunctival approach has been reported to have a lower risk of eyelid malposition and has subsequently gained in popularity. ${ }^{3}$ If skin redundancy needs to be addressed with the latter approach, the pinch technique or resurfacing can be concomitantly performed. ${ }^{4}$ Adjunctive eyelid-supporting procedures, such as lateral orbicularis suspension, canthopexy, or canthoplasty, as indicated for eyelid laxity can help reduce the risk of lower eyelid malposition in a transcutaneous approach. To quantify the change in eyelid position using the transcutaneous approach, we retrospectively reviewed standardized photographs from 100 consecutive patients who underwent this procedure and compared preoperative and postoperative measurements of lower eyelid position.

\section{Methods}

\section{Study Design and Population}

A retrospective medical record review of 100 consecutive transcutaneous lower eyelid blepharoplasties performed by the senior author (S.W.P.) in a private facial plastic surgery practice was conducted. Because this was a retrospective research study conducted in a private practice and not an academic center, there was no institutional review board oversight. All efforts related to study design and data collection were completed in accordance with the World Medical Association Declaration of Helsinki. ${ }^{5}$ All patients provided written informed consent for use of their photographs for data and research purposes before surgery, and all patients with photographs included in this article have given explicit written consent to have their photographs published. Patients with follow-up of less than 3 months, concurrent midface lift, and history of periocular trauma were excluded from the study. The operative reports were reviewed to extract data on concurrent operations and the use of fat transposition, extended malar approach, canthopexy, canthoplasty, or tarsorrhaphy. The skin-muscle flap blepharoplasties were performed with preservation of a pretarsal orbicularis strip and placement of an orbicularis suspension suture. $^{6}$

The medical records were reviewed postoperatively to determine whether any subsequent procedures, such as canthoplasty, tarsorrhaphy, revision transcutaneous lower eyelid surgery, transconjunctival removal of recurrent fat pseudoherniation, scar revision, corticosteroid injection into the

\section{Key Points}

Question What is the change in eyelid position after a transcutaneous skin-muscle flap approach for lower eyelid blepharoplasty?

Findings In this retrospective review of 100 consecutive patients, the mean increase in distance was $0.33 \mathrm{~mm}$ from the pupil to the lower eyelid margin and $0.32 \mathrm{~mm}$ from the lateral limbus to lower eyelid margin at final follow-up. Two patients required revision procedures secondary to eyelid malposition, and 25 patients had new onset of dry eye symptoms.

Meaning Transcutaneous skin-muscle lower eyelid blepharoplasty causes a small, predictable eyelid position change in this population with a low rate of revision procedures.

lower eyelid, and removal of lower eyelid nodules or milia, had been performed. Whether any patient reported preoperative or postoperative dry eye symptoms or chemosis was also recorded.

\section{Surgical Technique}

The procedure begins with a skin incision placed 2 to $3 \mathrm{~mm}$ inferiorly to the ciliary margin and extending medially from the lower punctum to a position 6 to $8 \mathrm{~mm}$ lateral to the lateral canthus within a natural skin crease. Lateral extension of the incision to this position minimizes rounding of the canthal angle, provides adequate visualization, and allows for orbicularis oculi muscle suspension. A pocket is created in the lateral aspect of the incision to identify the glistening white of the orbital septum. Blunt scissors are positioned posteriorly to the muscle at the lateral aspect of the incision, and the skin-muscle flap is elevated off the orbital septum by bluntly spreading in an avascular plane. The subciliary incision also involves preelevating the pretarsal skin flap to ensure the preservation of the pretarsal portion of the orbicularis oculi muscle. The incision is completed using a beveled cut, resulting in a stair-step configuration that minimizes the risk of postoperative lower eyelid malposition. Small openings overlaying the lateral, central, and medial compartments are made in the exposed orbital septum to access the orbital fat. Gentle ballottement of the globe results in herniation of orbital fat through the openings created in the orbital septum. Herniated fat is gently grasped, and bipolar cautery is used at the base of each fat pad before excision. Careful hemostasis is obtained to reduce the risk of bleeding and possible hematoma within the orbit after fat retraction posterior to the septum. The remaining fat volume is assessed by gentle palpation of the globe after resection.

In patients whose preoperative physical examination revealed a deep nasojugal groove or tear trough deformity, fat transposition of the nasal (medial) fat pocket and occasionally the central fat pocket is performed. The stalk of the visualized flap is positioned inferiorly beneath the orbicularis oculi and sutured to the periosteum using a braided absorbable suture. The aim of this additional procedure is to efface the depression in the nasojugal area while preserving or repurposing the orbital fat pocket. 


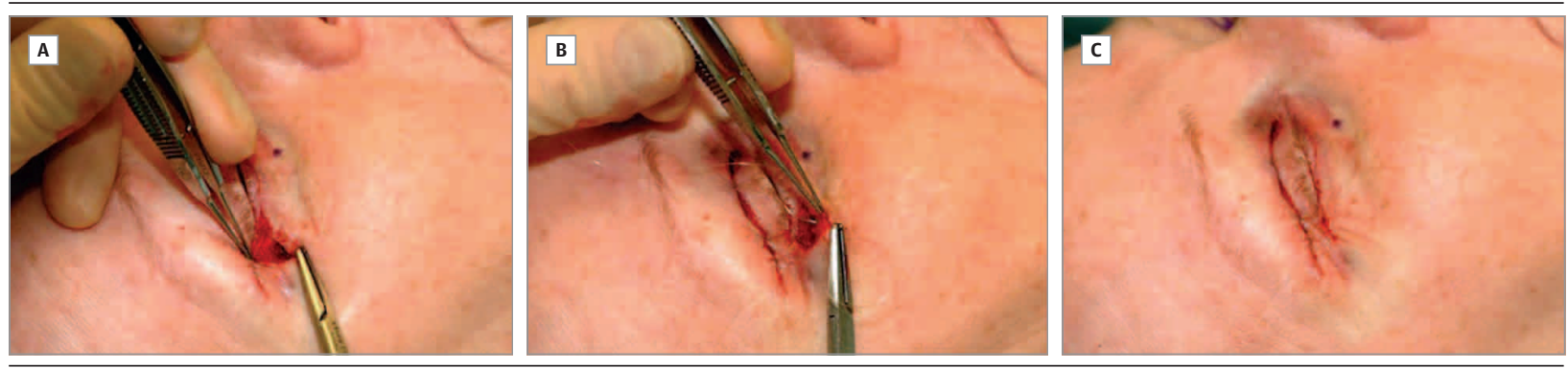

A, The periosteum of the lateral orbital rim at the level of the tubercle is grasped with a 5-0 Monocryl suture. B, The suture is passed through the orbicularis oculi muscle on the skin-muscle flap. C, The lower eyelid is suspended.

Before redraping the skin-muscle flap, an assistant applies single-finger pressure at the inferomedial portion of the melolabial mound to create the maximal stretch effect, similar to the awake patient opening her mouth and looking superiorly. This maneuver helps prevent overresection of skin and muscle. An inferiorly directed incremental cut is made in the skin at the lateral canthus, and the overlapping skin is conservatively excised. If orbicularis oculi muscle hypertrophy is evident, a 1- to 2-mm strip of muscle is resected to prevent muscular overlap and ridge formation with closure of the subciliary incision.

The orbicularis oculi muscle is then suspended to the periosteum of the lateral orbital rim using a 5-0 Monocryl suture (Ethicon Inc) in a buried fashion (Figure 1). After muscle suspension, the lateral aspect of the incision is closed with 7-0 blue polypropylene suture (Ethicon Inc) in a simple, interrupted fashion. The remainder of the subciliary incision is closed with 6-0 fast-absorbing gut suture (Ethicon Inc) in a simple running fashion.

Preoperative examination via the snap and distraction tests can dictate the need for eyelid-supporting procedures. Canthopexy or canthoplasty is easily performed at the time of blepharoplasty. In cases where there is slow but complete recoil on the snap test and no looseness in the lateral canthus on distraction, canthopexy is accomplished before closure of the upper and lower eyelid incisions. A suspension suture of 5-0 Monocryl is placed between the periosteum of the inner aspect of the superolateral orbital rim and the lower eyelid tarsus, lateral canthal tendon, and pretarsal orbicularis. The suture is tunneled under the bridge of skin between the upper and lower eyelid incisions. If an upper eyelid blepharoplasty is not performed at the time of canthopexy, a separate upper eyelid stab incision can be made at the superolateral orbital rim. A canthoplasty is performed in cases of significant eyelid laxity where eyelid distraction is greater than $6 \mathrm{~mm}$ or if the snap test results in the eyelid not returning to its original position or hanging in frank ectropion. Eyelid scissors are used to perform a lateral canthotomy and inferior cantholysis. Next, the lateral tarsal strip is created by excising conjunctiva from the posterior aspect of the tarsus and excising skin and muscle from the anterior aspect of the tarsus. The tarsal strip is then sutured to the periosteum of the medial aspect of the lateral orbital rim in a posterosuperior position with a 5-0 clear polypro-

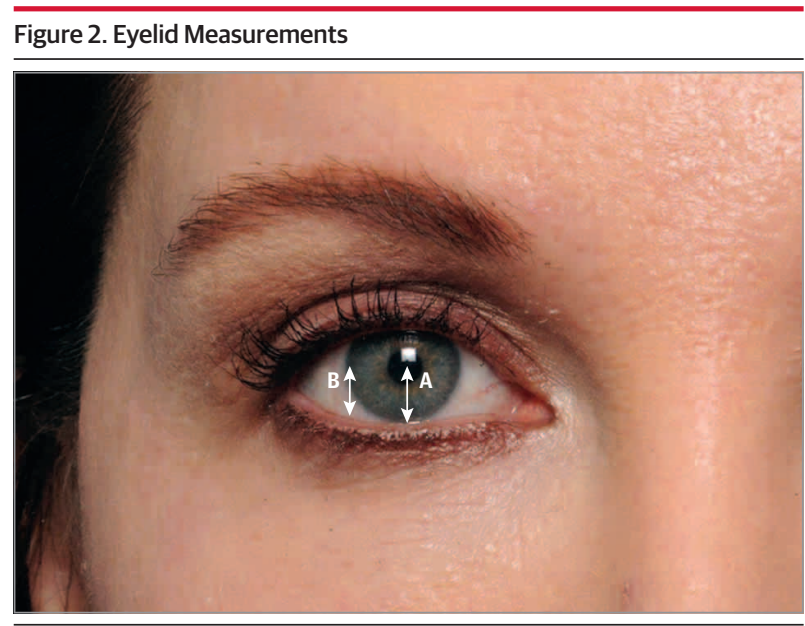

Measurements were made from the center of the pupil to the lower eyelid margin (A) and from the lateral limbus at the same vertical height as the center of the pupil to the lower eyelid margin (B).

pylene suture. The orbicularis oculi muscle is then suspended to the periosteum of the lateral orbital rim at the level of the Whitnall tubercle with a 5-0 Monocryl. The lower eyelid incision is then closed in the standard fashion.

\section{Photographic Analysis}

Preoperative and postoperative photographs were analyzed using United Imaging Inc software to standardize the intercanthal distance between images to allow for accurate comparison for each person. Normal values for the white to white diameter were used as a conversion factor to make all photographs comparable. ${ }^{7}$ Measurements were made from the center of the pupil to the lower eyelid margin and from the lateral limbus at the same vertical height as the center of the pupil to the lower eyelid margin (Figure 2). These measurements were made preoperatively, at 3 months postoperatively, and at the final follow-up visit.

\section{Statistical Analysis}

Univariate analysis was performed using 1-way analysis of variance for continuous variables and the Fisher exact test for categorical variables. Evaluation for independent associations of demographic and clinical characteristics with change in eyelid position was performed using multivariate linear regression, controlling for age, sex, concomitant fat transposition, 
and concomitant canthopexy. Age and sex were added empirically to the model, and independent variables with $P<.20$ on univariate analysis (fat transposition and canthopexy) were included in the final model. One individual (1.0\%) underwent a revision lower eyelid procedure before the 3-month follow-up visit and was excluded from all analyses of change in eyelid position, and 5 individuals (5.0\%) underwent a revision lower eyelid procedure because of persistent fat pseudoherniation or skin redundancy and were excluded from final follow-up analyses. Data were analyzed using STATA statistical software, version 13.1 (StataCorp). A 2-sided threshold of $P<.05$ was used to evaluate statistical significance.

Table 1. Demographics and Procedures Performed in the 100 Study Patients

\begin{tabular}{|c|c|}
\hline Variable & Finding $^{\mathrm{a}}$ \\
\hline Age (continuous), mean (SD) [range], y & $56.7(8.4)[31-74]$ \\
\hline \multicolumn{2}{|l|}{ Age (categorical), y } \\
\hline$\leq 49$ & $13(13.0)$ \\
\hline $50-60$ & $53(53.0)$ \\
\hline$\geq 61$ & $34(34.0)$ \\
\hline Female & $92(92.0)$ \\
\hline Mean duration of follow-up, mo & 10.7 \\
\hline \multicolumn{2}{|l|}{ Concomitant procedures } \\
\hline Any procedure & $88(88.0)$ \\
\hline Fat transposition & $69(69.0)$ \\
\hline Malar extension & $14(14.0)$ \\
\hline Canthopexy & $22(22.0)$ \\
\hline Canthoplasty & $7(7.0)$ \\
\hline Submalar implant & $1(1.0)$ \\
\hline Tarsorrhaphy & $1(1.0)$ \\
\hline \multicolumn{2}{|l|}{ Revision procedure(s) } \\
\hline \multicolumn{2}{|l|}{ Bilateral } \\
\hline Canthoplasty & $2(2.0)$ \\
\hline Transcutaneous revision blepharoplasty & $2(2.0)$ \\
\hline Transconjunctival revision blepharoplasty & $3(3.0)$ \\
\hline Unilateral transconjunctival revision blepharoplasty & $2(2.0)$ \\
\hline Other $^{\mathrm{b}}$ & $11(11.0)$ \\
\hline Scar revision & $2(2.0)$ \\
\hline Removal of suture nodules or milia & $9(9.0)$ \\
\hline Triamcinolone acetonide injection(s) & $42(42.0)$ \\
\hline \multicolumn{2}{|c|}{$\begin{array}{l}\text { Data are presented as number (percentage) of patients unless otherwise } \\
\text { noted. }\end{array}$} \\
\hline Procedures without effect on eyelid position. & \\
\hline
\end{tabular}

\section{Results}

Data from 100 consecutive patients undergoing bilateral skin-muscle flap lower eyelid blepharoplasty were analyzed. Mean age was 56.7 years, and 92 patients (92.0\%) were female. The mean follow-up for the patients was 10.7 months (Table 1). Fat transposition was performed in 69 patients (69.0\%), canthopexy was performed in 22 patients (22.0\%), and canthoplasty was performed in 7 patients (7.0\%). Two patients (2.0\%) requested bilateral canthoplasties secondary to eyelid malposition. A total of 11 (55.0\%) of the other revision procedures were attributable to unilateral removal of milia or minor scar revision. Forty-two patients $(42.0 \%)$ required at least 1 triamcinolone acetonide injection secondary to eyelid thickness and stiffness to help release the temporary contraction within the middle lamella. When concomitant operations by age group were analyzed (Table 2), canthopexy was exclusively performed on patients older than 50 years, and individuals 61 years or older significantly more often underwent canthoplasty compared with younger individuals $(P=.01)$.

The increase in distance from the pupil to lower eyelid margin in all patients was $0.41 \mathrm{~mm}(95 \% \mathrm{CI}, 0.32-51 \mathrm{~mm})$ at 3 months and $0.33 \mathrm{~mm}$ (95\% CI, 0.24-0.42 mm) at final followup. At final follow-up, men had a significantly greater change in distance than women $(0.76 \mathrm{~mm}$; 95\% CI, 0.44-1.08 mm, vs $0.30 \mathrm{~mm}$; 95\% CI, 0.20-0.39 mm, respectively; $P=.008$ ), and individuals undergoing canthopexy had a significantly greater change than those who did not $(0.65 \mathrm{~mm}$; 95\% CI, 0.45-0.85 $\mathrm{mm}$, vs $0.25 \mathrm{~mm}$; 95\% CI, 0.15-0.35 mm, respectively; $P<.001)$. Patients undergoing fat transposition had a small change $(0.37$ mm; 95\% CI, 0.27-0.48 mm, vs 0.22 mm; 95\% CI, 0.05-0.40 $\mathrm{mm}$, respectively; $P=.13$ ).

The change in distance from lateral limbus to lower eyelid margin in all patients was $0.47 \mathrm{~mm}$ (95\% CI, 0.37-0.56 $\mathrm{mm})$ at 3 months and $0.32 \mathrm{~mm}(95 \% \mathrm{CI}, 0.23-0.41 \mathrm{~mm})$ at final follow-up. Individuals undergoing canthopexy had a significantly greater mean change in the distance from lateral limbus to lower eyelid compared with those who did not (0.66 mm; 95\% CI, 0.48-0.84 mm, vs 0.24 mm; 95\% CI, 0.14-0.33 $\mathrm{mm} ; P<.001)$. Patients undergoing fat transposition had a small change $(0.37 \mathrm{~mm}$; 95\% CI, 0.27-0.48 mm, vs $0.19 \mathrm{~mm}$; $95 \% \mathrm{CI}, 0.03-0.35 \mathrm{~mm}$, respectively; $P=.07$ ).

Multivariate linear regression was performed to examine for associations of demographic and clinical characteristics with

Table 2. Concomitant Operations by Age Group in the 100 Study Patients

\begin{tabular}{|c|c|c|c|c|}
\hline \multirow[b]{2}{*}{ Procedure } & \multicolumn{3}{|c|}{ No. (\%) of Operations by Age Group } & \multirow[b]{2}{*}{$P$ Value $^{\mathrm{a}}$} \\
\hline & $\begin{array}{l}\leq 49 y \\
(n=13)\end{array}$ & $\begin{array}{l}50-60 y \\
(n=53)\end{array}$ & $\begin{array}{l}\geq 61 \text { y } \\
(n=34)\end{array}$ & \\
\hline Fat transfer & $11(84.6)^{b}$ & 38 (71.7) & $20(58.8)$ & .21 \\
\hline Malar extension & 0 & $7(13.2)$ & $7(20.6)$ & .22 \\
\hline Canthopexy & 0 & $13(24.5)$ & $9(26.5)$ & .11 \\
\hline Canthoplasty & 0 & $1(1.9)$ & $6(17.6)$ & .01 \\
\hline Submalar implant & 0 & $1(1.9)$ & 0 & $>.99$ \\
\hline Tarsorrhaphy & 0 & 0 & $1(2.9)$ & .47 \\
\hline
\end{tabular}

${ }^{\text {a }}$ Differences between subgroups were analyzed using the Fisher exact test. A 2-sided threshold of $P<.05$ was used to evaluate statistical significance.

${ }^{\mathrm{b}}$ Number (percentage within associated age category). 
Table 3. Multivariate Regression Models Examining the Effect of Independent Demographic and Clinical Characteristics on Change in Distance in the Pupil to Lower Eyelid From Baseline to Final Follow-up in 94 Study Patients ${ }^{a}$

\begin{tabular}{|c|c|c|}
\hline Independent Variable & Coefficient $(95 \% \mathrm{Cl})$ & $P$ Value \\
\hline \multicolumn{3}{|l|}{ Age (categorical), y } \\
\hline$\leq 49$ & [Reference] & NA \\
\hline $50-60$ & $-0.18(-0.44$ to 0.09$)$ & .19 \\
\hline$\geq 61$ & $-0.25(-0.53$ to 0.04$)$ & .09 \\
\hline \multicolumn{3}{|l|}{ Sex } \\
\hline Male & [Reference] & NA \\
\hline Female & $-0.40(-0.73$ to -0.07$)$ & .02 \\
\hline \multicolumn{3}{|l|}{ Fat transposition } \\
\hline Not performed & [Reference] & NA \\
\hline Performed & $0.08(-0.12$ to 0.28$)$ & .43 \\
\hline \multicolumn{3}{|l|}{ Canthopexy } \\
\hline Not performed & [Reference] & NA \\
\hline Performed & $0.42(0.20$ to 0.64$)$ & $<.001$ \\
\hline
\end{tabular}

Abbreviation: NA, not applicable.

a Models were adjusted for age, sex, fat transposition, and canthopexy. Age and sex were included empirically. Fat transposition and canthopexy were included because of an association $(P<.05)$ or possible association $(P<.20)$ with change in distance on univariate analysis. Six patients were excluded because of a revision procedure that may have affected eyelid position before final follow-up.

change in distance from pupil and lateral limbus to eyelid margin. Each model was adjusted for age, sex, concomitant fat transposition, and concomitant canthopexy. In the model for change in distance from pupil to eyelid margin (Table 3), female sex had a significant independent inverse association (coefficient, -0.40 ; 95\% CI, -0.73 to $-0.07 ; P=.02$ ), and canthopexy had a significant independent positive association (coefficient, 0.42; 95\% CI, 0.20-0.64; $P<.001$ ) with change in distance. In the multivariate model for change in distance from lateral limbus to eyelid margin (Table 4), canthopexy had a significant independent positive association (coefficient, 0.43; 95\% CI, 0.22-0.65; $P<.001$ ) with change in distance.

Of the 82 patients without preoperative dry eye, 25 developed dry eye symptoms after surgery. No significant association was found between change in eyelid distance (pupil or lateral limbus to eyelid) and development of dry eye symptoms for all individuals. Individuals who underwent fat transposition (22/82 [38.6\%]) significantly more often developed new-onset dry eye symptoms compared with those that did not undergo fat transposition (3/82 [12.5\%], $P=.03)$.

\section{Discussion}

The ideal approach to addressing the lower eyelid is a source of debate, principally between the transcutaneous and transconjunctival approaches. ${ }^{8-18}$ Concerns have been raised regarding postoperative lower eyelid malposition with the transcutaneous approach, and a perception of a better safety profile with the transconjunctival approach has subsequently developed. ${ }^{19,20}$ However, in the present study of 100 consecutive patients undergoing bilateral transcutane-
Table 4. Multivariate Regression Models Examining the Effect of Independent Demographic and Clinical Characteristics on Change in Distance in the Lateral Limbus to Lower Eyelid From Baseline to Final Follow-up in 94 Study Patients ${ }^{\mathrm{a}}$

\begin{tabular}{|c|c|c|}
\hline Independent Variable & Coefficient $(95 \% \mathrm{Cl})$ & $P$ Value \\
\hline \multicolumn{3}{|l|}{ Age (categorical), y } \\
\hline$\leq 49$ & [Reference] & NA \\
\hline $50-60$ & $0.00(-0.27$ to 0.26$)$ & .98 \\
\hline$\geq 61$ & $-0.06(-0.35$ to 0.22$)$ & .66 \\
\hline \multicolumn{3}{|l|}{ Sex } \\
\hline Male & [Reference] & NA \\
\hline Female & $0.25(-0.08$ to 0.58$)$ & .14 \\
\hline \multicolumn{3}{|l|}{ Fat transposition } \\
\hline Not performed & [Reference] & NA \\
\hline Performed & $0.19(0.00$ to 0.39$)$ & .06 \\
\hline \multicolumn{3}{|l|}{ Canthopexy } \\
\hline Not performed & [Reference] & NA \\
\hline Performed & $0.43(0.22$ to 0.65$)$ & $<.001$ \\
\hline
\end{tabular}

Abbreviation: NA, not applicable.

${ }^{\text {a }}$ Models were adjusted for age, sex, fat transposition, and canthopexy. Age and sex were included empirically. Fat transposition and canthopexy were included because of an association $(P<.05)$ or possible association $(P<.20)$ with change in distance on univariate analysis. Six patients were excluded because of a revision procedure that may have affected eyelid position before final follow-up.

ous skin-muscle flap lower eyelid blepharoplasties with selective use of canthoplasty or canthopexy, only 2 patients required revision procedures because of eyelid malposition, and the change in eyelid position in all patients from baseline to final follow-up was less than $0.5 \mathrm{~mm}$. Patients undergoing canthopexy had a greater pupil to eyelid and lateral limbus to eyelid position change than patients not undergoing canthopexy. This finding is not unexpected given that patients undergoing canthopexy likely had weaker eyelid support preoperatively. Some surgeons advocate routine canthal support ${ }^{16,21}$; however, if further eyelid support is unneeded, the patient may assume unnecessary additional risks of canthoplasty or canthopexy. ${ }^{22}$ Therefore, it is necessary to thoroughly examine each patient and selectively perform these procedures.

Maffi et $\mathrm{al}^{23}$ reported a series of 2007 patients undergoing transcutaneous blepharoplasty without eyelid-anchoring procedures and found only 8 lower eyelid malposition complications. However, their study did not include patients with greater than $6 \mathrm{~mm}$ of eyelid distraction preoperatively. Patients with weakened lower eyelid support may require additional procedures, such as canthopexy and canthoplasty. Lower eyelid malposition as a complication of lower eyelid surgery has been reported to range from $5 \%$ to $30 \% .^{24-27}$ The present study illustrates that the transcutaneous skin-muscle flap approach can be performed with a minor and predictable change in lower eyelid position with a low rate of revision. The particular approach for patients in this study used canthopexy and canthoplasty when indicated. Portions of the procedure that are vital to minimization of eyelid position change include sparing of the pretarsal orbicularis oculi, placement of the orbicularis suspension suture, and a thorough preoperative eyelid 
Figure 3. Preoperative and Postoperative Photographs With Fat Transposition

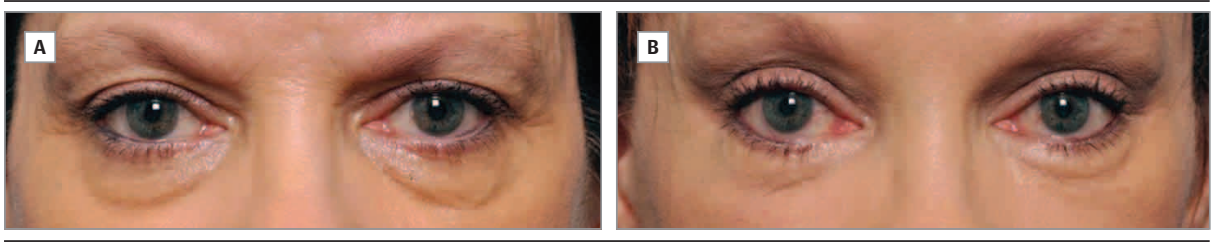

A, Preoperative photograph of a patient who underwent skin-muscle flap lower eyelid blepharoplasty with fat transposition. B, Postoperative photograph shows the change in lower eyelid position and dry eyes.

Figure 4. Preoperative and Postoperative Photographs With and Without Fat Transposition
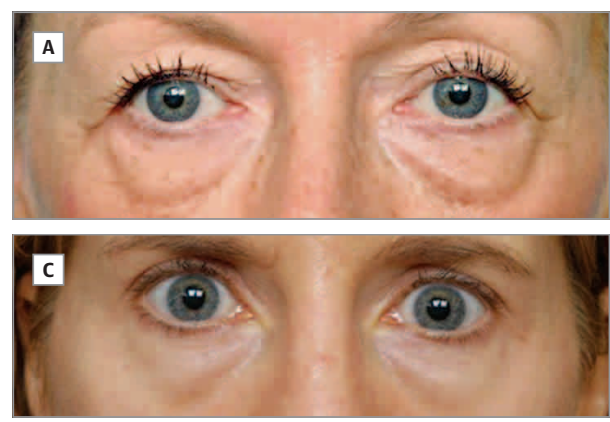

A, Preoperative photograph of a patient who underwent skin-muscle flap lower eyelid blepharoplasty. B, Postoperative photograph shows removal of pseudoherniated fat and correction of vertical skin excess. C, Preoperative photograph of a patient who underwent skin-muscle flap lower eyelid
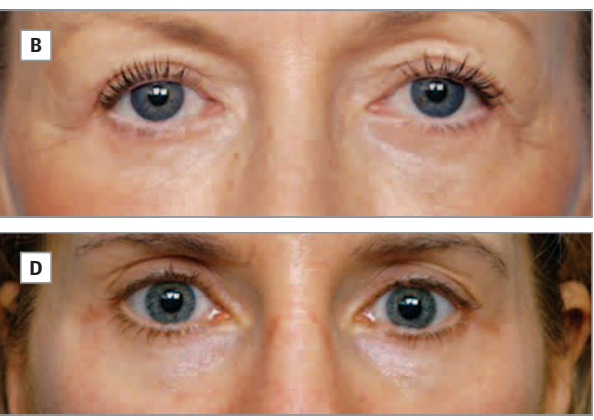

blepharoplasty with fat transposition. A deep medial nasojugal groove is present. D, Postoperative photograph shows effacement of the contour abnormality after fat transposition. strength evaluation to determine whether any adjunctive procedures are needed. In cases where there is slow but complete recoil on the snap test and no looseness in the lateral canthus on distraction, canthopexy should be performed. In cases of significant eyelid laxity where eyelid distraction is greater than $6 \mathrm{~mm}$ or if the snap test results in the eyelid not returning to its original position or hanging in frank ectropion, canthoplasty should be performed.

Dry eye symptoms were recorded to determine whether there was an association with distances measured. There were 25 cases (30.5\%) of new-onset dry eye symptoms in the first 3 months, which is similar to numbers reported in a previous study, ${ }^{28}$ but no association was found with the change in distance. This finding supports that the eyelid position changes were of little clinical significance. Patients undergoing fat transposition had a higher chance of developing dry eye possibly because of the combination effect of the inferior transposition causing greater eyelid position change and more orbicularis disruption (Figure 3). Fat transposition is an effective procedure for treating a deep nasojugal groove (Figure 4) but should be used judiciously.

This study is retrospective and is therefore subject to limitations. Only associations can be found, and causal inferences cannot be made. Given the retrospective nature of the data collection, errors or omissions in documentation of information cannot be excluded. However, the series is consecu- tive and therefore limits selection bias. In addition, the procedure was standardized for all patients and performed by a single surgeon (S.W.P.), limiting protocol deviation as a source of variance in the data. In a retrospective study, it is not possible to look at other relevant factors, such as malar support, globe prominence, skin quality, and ocular surface quality; hence, our patient population may not reflect other physicians' patient populations. Eyelid position measurements used provided information on lower eyelid retraction, but these measurements do not capture the complete change in position and shape of the lower eyelid or 3-dimensionally capture ectropion. The clinical significance of eyelid position change was evaluated by measuring revision rates, but a more sensitive approach would have been to include a patient satisfaction survey that incorporated eyelid position and any scleral show if present.

\section{Conclusions}

The transcutaneous skin-muscle lower eyelid blepharoplasty causes a minor lower eyelid position change with only a $2 \%$ revision rate secondary to eyelid malposition. Preservation of the pretarsal orbicularis, orbicularis suspension, and selective use of canthopexy and canthoplasty result in predictable lower eyelid positions.
ARTICLE INFORMATION

Accepted for Publication: March 21, 2016

Published Online: July 7, 2016.

doi:10.1001/jamafacial.2016.0673.
Author Contributions: Drs Sultan and Genther had full access to all the data in the study and take responsibility for the integrity of the data and the accuracy of the data analysis. Study concept and design: Sultan, Perkins.
Acquisition, analysis, or interpretation of data: Sultan, Genther.

Drafting of the manuscript: Sultan, Critical revision of the manuscript for important intellectual content: All authors. Statistical analysis: Sultan, Genther. 
Administrative, technical, or material support: Perkins.

Study supervision: Perkins.

Conflict of Interest Disclosures: None reported.

Additional Contributions: Nancy Rothrock, BFA and Debby Crevonis, BA, assisted with photographs; Melissa Mumaw retrieved medical records for the study. No compensation was provided

\section{REFERENCES}

1. Perkins SW, Prischmann J. The art of blepharoplasty. Facial Plast Surg. 2011;27(1):58-66.

2. Edgerton MT Jr. Causes and prevention of lowe lid ectropion following blepharoplasty. Plast Reconstr Surg. 1972;49(4):367-373.

3. Zarem HA, Resnick Jl. Minimizing deformity in lower blepharoplasty: the transconjunctival approach. Clin Plast Surg. 1993;20(2):317-321.

4. Parkes M, Fein W, Brennan HG. Pinch technique for repair of cosmetic eyelid deformities. Arch Ophthalmol. 1973;89(4):324-328.

5. Association WM; World Medical Association. World Medical Association Declaration of Helsinki: ethical principles for medical research involving human subjects. JAMA. 2013;310(20):2191-2194.

6. Shadfar S, Perkins SW. Transcutaneous skin-muscle flap suspension lower-eyelid blepharoplasty. JAMA Facial Plast Surg. 2015;17(6) 459-461.

7. Rüfer F, Schröder A, Erb C. White-to-white corneal diameter: normal values in healthy humans obtained with the Orbscan II topography system. Cornea. 2005;24(3):259-261.

8. Netscher DT, Patrinely JR, Peltier M, Polsen C Thornby J. Transconjunctival versus transcutaneous lower eyelid blepharoplasty: a prospective study. Plast Reconstr Surg. 1995;96(5):1053-1060.
9. Jacono AA, Moskowitz B. Transconjunctival versus transcutaneous approach in upper and lowe blepharoplasty. Facial Plast Surg. 2001;17(1):21-28.

10. Baylis HI, Long JA, Groth MJ. Transconjunctival lower eyelid blepharoplasty: technique and complications. Ophthalmology. 1989;96(7): 1027-1032.

11. Weinberg DA, Baylis HI. Transconjunctival lower eyelid blepharoplasty. Dermatol Surg. 1995;21(5): 407-410.

2. Adamson PA, Strecker HD. Transcutaneous lower blepharoplasty. Facial Plast Surg. 1996;12(2): 171-183.

13. Kikkawa DO, Kim JW. Lower-eyelid blepharoplasty. Int Ophthalmol Clin. 1997;37(3): 163-178.

14. Rizk SS, Matarasso A. Lower eyelid blepharoplasty: analysis of indications and the treatment of 100 patients. Plast Reconstr Surg 2003;111(3):1299-1306.

15. Nassif PS. Lower blepharoplasty: transconjunctival fat repositioning. Otolaryngol Clin North Am. 2007:40(2):381-390.

16. Codner MA, Wolfli JN, Anzarut A. Primary transcutaneous lower blepharoplasty with routine lateral canthal support: a comprehensive 10-year review. Plast Reconstr Surg. 2008;121(1):241-250.

17. Weinfeld AB, Burke R, Codner MA. The comprehensive management of chemosis following cosmetic lower blepharoplasty. Plast Reconstr Surg. 2008:122(2):579-586.

18. Korn BS, Kikkawa DO, Cohen SR

Transcutaneous lower eyelid blepharoplasty with orbitomalar suspension: retrospective review of 212 consecutive cases. Plast Reconstr Surg. 2010;125(1) 315-323.
19. McGraw BL, Adamson PA. Postblepharoplasty ectropion: prevention and management. Arch Otolaryngol Head Neck Surg. 1991;117(8):852-856.

20. McCord CD Jr, Ellis DS. The correction of lower lid malposition following lower lid blepharoplasty. Plast Reconstr Surg. 1993;92(6):1068-1072.

21. Flowers RS. Canthopexy as a routine blepharoplasty component. Clin Plast Surg. 1993;20 (2):351-365.

22. Kim DY, Lelli GJ Jr. Delayed orbital hematoma after lateral canthoplasty. Ophthal Plast Reconstr Surg. 2010;26(6):481-483.

23. Maffi TR, Chang S, Friedland JA. Traditional lower blepharoplasty: is additional support necessary? a 30-year review. Plast Reconstr Surg. 2011;128(1):265-273.

24. Fagien S. Algorithm for canthoplasty: the lateral retinacular suspension: a simplified suture canthopexy. Plast Reconstr Surg. 1999;103(7): 2042-2053.

25. Jacobs SW. Prophylactic lateral canthopexy in lower blepharoplasties. Arch Facial Plast Surg. 2003;5(3):267-271.

26. Putterman AM. Cosmetic Oculoplastic Surgery. New York, NY: Grune \& Stratton; 1982.

27. DiFrancesco LM, Anjema CM, Codner MA, McCord CD, English J. Evaluation of conventional subciliary incision used in blepharoplasty: preoperative and postoperative videography and electromyography findings. Plast Reconstr Surg. 2005;116(2):632-639.

28. Prischmann J, Sufyan A, Ting JY, Ruffin C, Perkins SW. Dry eye symptoms and chemosis following blepharoplasty: a 10-year retrospective review of 892 cases in a single-surgeon series. JAMA Facial Plast Surg. 2013;15(1):39-46. 